\title{
The Analysis of the Coexistence between Sport and the Media in the Modern Society
}

\author{
LEI LU ${ }^{1, a}$, WENJUN WU ${ }^{2, b, *}$
}

\author{
${ }^{1}$ Department of Basic Teaching, Beijing Institute of Fashion Technology No.2 A2, East Yinghua \\ Street, Chaoyang District, Beijing, 100029, China \\ ${ }^{2}$ Department of Sport Teaching, Xin Jiang Institute of Light Industry Technology, Xin Jiang, 830021, \\ China \\ âEmail:Leilu122@126.com, bemail:wenjunwu123@126.com, *corresponding author
}

Keywords: Coexistence, Sport and Media, Global T.V Coverage, Modern Society, Sport Attraction

\begin{abstract}
This paper is aimed to analysis briefly the coexistence between sport and the media in the modern society. I analyzed their inter-relationship from three perspectives: attraction and influence, increase benefit, and global T.V coverage. Data observation, literature review, reflective journals were used to how sport attraction and influence occurred when the popularization of media and further explore some important factors and inter-relationship about sport and media industry in the contemporary era. The results indicate that sport managers can further cognize sport and media have developed an interdependent relationship.
\end{abstract}

\section{Introduction}

Since the first televised sporting event was a college baseball game between Columbia and Princeton in 1939, covered by one camera providing a point of view along the third base line, the sports and the media are rapidly growing together in the planet, especially at last decade, their inter-relationship has become of particular interest to media scholars. According to Kinkema and Harris, 'there are occasions when as many as ten sporting events are televised simultaneously'[9]. Many recent developments within mass sport have been guided by economic considerations that can easily be traced back to the media. Therefore sport needs the media to help them effort to become multi-million industries and media needs sport to capture the audiences and reflect the culture of sport and consumers, particularly in the development of media, sport for its important part has transformed the media.

\section{The Media Need Sport Attraction}

According to Beck and Bosshart (2003), 'sports have become an integral source of entertainment for contemporary societies because spectator sports have every single ingredient of delightful entertainment, further indicated that the media make the sports an important public issue and, sell them[3].'

In themselves, sports as same as a reliable mirror of societies, they are strongly linked to the prevailing lifestyles in modern societies. They reflect social values that can extend from individual values and generally accepted values. Andrew(2005) indicated that 'the media has an important and growing role in the culture of developed countries... if media organizations want to remain successful in competitive market, the media not only reflect the culture in which they operate and the interests of their readers and views, they also help to form that culture and those interest [1].

The media has the most of news are unpredictable commodity in the world, but sport is the exact opposite, it is always predictable in the sport events. Thus media already have recognized the power of sport for a long time. It is regarded as one of the cornerstones of content that is consumed better than anything else. News, drama, opinion...it's difficult to capture such a large market, but sports has always delivered[19]. (cycling trip, online, 2011) For instance, SKY TV company and YouTube 
website has used successfully sport events to sell subscriptions to their sport channels.

Media and sport have always had symbiotic relationship, without one the other does not exist. Sometime, media has an important impact on sport area, there have many examples to identified media demands can fundamentally change the sport itself.

For example, on the 2008 Beijing Olympics, according to NBC's financial muscle, NBC persuade the IOC to change the time on the final swimming heats to 8am (Beijing time) so that the American public could watch Michael Phelps win his 8 gold medals in prime time[13]. Further, using this time form to attract more spectators and advertise companies, and increasing their audience rating, it makes effort to break their revenue chain and enhance their financial power.

There has another case of the media's influence and demand on sport, when NBC struck a deal with the NFL whereby they wanted to show the best games on Sunday nights. They convinced the NFL to have a flexible schedule whereby they completely adjustment the match-ups in part of the season so that the best games are broadcast on Sunday night to accommodate the television viewing audience (therefore absorbing advertisers and sponsors).

Reference: NBC news-sports online[13]

Due to media built structure of the sports development and receive the sports consumers' feedback about sports information, the media has the best chance to create bridge between sporting events and audience, (include the readers, listeners and viewers), moreover, deep understanding the satisfaction and tastes from the sponsor and spectators. At the same time, the media can take some opportunities to encourage the spectators enter the unfamiliar sport area, such as diving, cricket, equestrian, horse racing. The media already focus on niche markets for these minority sports and traditional sports. For instance, refer to the favorites for BBC's Sport Personality of Past winners on the last decade, we clear found that the players of minority sports already become dominated competitors in final election[18]. The victor's lists include that: (1)Tony Mccoy (Horse racing) in the 2010years; (2)Chris Hoy (Cycling) in the 2008 years; (3)Zara Phillips (Equestrian) in the 2006 years; (4)Andrew Flint off (Cricket) in the 2005 years.

Source from: BBC Sport Personality online [18].

Media organizations reply on sports market standard, they have fast grown and adapted accordingly, so new radio stations and television channels already enter into sport territory. Andrews (2005) explains that 'media has been a similar growth in specialist and lifestyle publications aimed at specific sections of the media audience [1], such as young men.

However, in the media industry, there has new battle for television ratings between public and commercial sectors. The satellite channels are forced to contest with the terrestrial TV and cable channels, to retain their share of the target market.

Owing to sport creates value for money to advertiser and sponsors, thus they apply this approach of guiding niche audience to offer many interesting and important for the media. This factor will be analyzed further in the second part of the report.

However Bernstein and Blain (2003) stated that the sport media has many violence on-screen, males constitute the majority of the audience for violent films [4], as well as violent sports such as [American] football and boxing. Thus some famous players give little bad models o the children by cheating, swearing and showing violent during live games. For instance, before last year famous players Mike Tyson, he was biting his opponent's ear in the boxing game [11]; football star Wayne Rooney swore into a live TV camera after scoring against West Ham at Upton Park [2].

According to Daniel and Sullivan, 'Television is the most important medium for sports reports but the internet offers interesting options for sports fan today [10].' There has created many sport website on last several years, such as BBC represents the media organizations, and Manchester United represents the famous sport clubs and B win represents the Bookmakers which is currently sponsoring Real Madrid Football Club and Euro League Basketball. Therefore, these websites hope to earn huge money from the different of sports.

\section{Sport Organizations Increase Benefit by Using the Media}

At present, media need sport information to fill their screen and board, but sport organizations 
according to media facilities to open communication with customers and attract potential consumers of their products, furthermore, it helps them to build their brand in public society. Besides, the sports organizations have use media develop to increase their revenue and retain their market share not merely from media rights, but also from sponsorship, advertising.

Since internet is growing, there have appeared many communication tools by website in the world. Such as Facebook, Twitter, MSN etc. these communication tools take huge effect of economic in the sport territory. As Thomas (1998) indicated 'Internet technology is an opportunity for the clubs to enhance their marketing activities by establishing a more direct communication with supporters and customers.' For example, The National Basketball Association, is the most social media of all the sports in the world. According to Fast Company, The NBA has more than 6.7millioin combined Facebook fans and Twitter followers, and it's not satisfied just having those followers, Teams go the great lengths to engage them [16].

On the 2010 spring season, the Golden State Warriors were set to unveil a new team logo. Rather than leak it through press as every club in every sports does, they took to Facebook, Twitter, Flickr and YouTube [8]. Over the course of nine weekdays, the Warriors asked fan one trivia question each day via the various social media outlets. Each time a fan answered the question correctly he would get access to a fraction of the team's logo, until on the final day, the complete logo appeared. It provides a great chance to get fans talking about the brand, and encourage potential consumers buy their merchandise.

At the recreational level, on the one side, the Qatar football organization has hosted a charity soccer match featuring stars from the 2002 World Cup final between Brazil and Germany to raise funds for the victims of the Japanese tsunami and earthquake in DOHA on December 2011[5]. It has been a real success as the ESPN and the different mediums included the broadcast company has supported and encouraged the charity program.

On the other side, the media reflect with traditional culture and from this new alliance, in order to bridge the global gap on different continents. For instance, the Guangzhou Ever grade Football Club using financial groups connect with Real Madrid technical group together to invest the biggest football school of Asia in Guangdong Qingyuan city of China [14]. They will according to media supporting, to develop Chinese football level, even though contribute to whole Asian hierarchy.

Advertising is essential to building a business. Sports organizations need a good advertise to sponsor their team, further their will increase their revenue streams. As sports organizations have a presence on the television, internet and radio and, of course, the venue of games, sponsorship can be anything from providing services to buying naming rights to the team's stadium.

Sponsors are investing a huge of money into organizations, clubs and athletes to keep their brand and logo in the public eye. They want to see their brand mark on the merchandises and attending all sports events. Thus the media easily engages journalists and programs to create a special media platform between sport industry and business territory, they offer all the information, details and statistics for the every event. Reviewing international events, they found that top sponsor companies have authority press office to offer relevant information and supply their sponsor teams running and managing for the medium.

According to 2011 Forbes Soccer valuation list (refer with: Table 1), Manchester United is still the world's most valuable football club in the world and its revenue for the year 2011 was \$428millions included the match day, broadcasting, sponsorship and commercial incomes[17].

\section{The Global T.V Coverage on Globalization}

According to Bernstein and Blain (2003), Sport has come to express ideas about 'competition, excellence, corporate efficiency, and what it is necessary to do to win - ideas that have their origins in the United States' [4]. In this sense the American style of sport has become the international example for corporate sport around the world; offering business elements, the ability to attract sponsors and, not least, displaying telegenic quality. According to media industry rapidly developing in the world, the sport already become global industry. The spread of modern sport is 
revenue chains, at the same time, the media industry need sport resources to sell their broadcasting rights and some relative products. The successful coverage of sports has enormous influence in the playing sports events, even some elite players directly attract to more mass media and sponsors.

However, due to the sport media has rapidly developed, they brought a few disadvantages in modern society. We must correctly deal with these problems. Therefore the government should be increase educational programs to help these organization solving problems. Further it enhanced their potential sense to create the biggest value in commercial territory.

\section{Reference List:}

[1] Andrews P. (2005). Sports Journalism: A Practical Introduction. London: Sage

[2] BBC Sport online. Published the 13 April 2011. [online]. Man United's Wayne Rooney explains swearing mistake. Information http://news.bbc.co.uk/sport2/hi/football/teams/m/man_utd/9456685.stm

[3] Beck, Daniel and Bosshart, Louis (2003). Sports and Media. Volume 22, 4-5. [online]. Article from the Centre for the Study of Communication and Culture. University of Fribourg. Last accessed 7 April 2011.

[4] BERNSTEIN Alina and BLAIN Neil (2003). Sport, Media, Culture: global and local dimensions. London, Frank Cass.

[5]Charity Match To Benefit Japan. (2011) [online].Information on: http://espn.go.com/sports/soccer/news/_id/6395164/qatar-charity-match-help-japan-quake-victims

[6] FIFA Financial Report 2010. (2010). [online]. Information on: http://www.fifa.com/

[7] Gardiner, S. et al. (2006). Sports Law, 3rd Edition., London, Cavendish

[8] Golden State Warriors Unveil New Logo, Color Scheme and Branding Elements. (2010) [online] Information on: http://www.nba.com/warriors/news/warriors_unveil_new_logo_061710.html

[9] K.M. KINKEMA AND J.C. Harris, 'Media sport Studies: Key Research and Emerging Issues', in L.A. Wenner (ed.), Media Sport (London: Routledge, 1998), p.27.

[10] Mc Daniel. S. R., \& Sullivan, C. B. (1998). Extending the sports experience: Mediating in cyberspace. In L.A. Wenner (Ed.), Mediasport. London and New York: Routledge.

[11] Mimicked Tyson, Boxer Biting His Opponent's Ear. (2011). [online] Information on: http://www.summarynewspaper.com/mimicked-tyson-boxer-biting-his-opponents-ear/1157.html

[12] NBA Outpaces NFL,MLB With Most Facebook, Twitter Followers. (2010) [online] Information on:http://www.sportsbusinessdaily.com/Daily/Issues/2010/10/Issue-32/NBA-Season-Preview/NBAOutpaces-NFL-MLB-With-Most-Facebook-Twitter-Followers.aspx

[13] News-Sports.(2008). [online]. Information on: http://www.nbc.com/

[14] Official website of Guangzhou Hengda Football club. [online]. Information on: http://www.gzevergrandefc.com/

[15] Information on: http://www.olympic.org

[16] Information on: http://www.fastcompany.com

[17] Richest Football Clubs 2011-World's most valuable soccer teams. (2011). [online]. Information on: http://www.therichest.org/sports/forbes-richest-football-teams/

[18] Sports Personality of The Year. (2011). [online]. Information on: http://www.bbc.co.uk/sport/0/sports-personality/16303729 
[19] The Media's Influence On Sport. (2011). [online]. Information on: http://www.cyclingtips.com.au/2011/06/the-medias-influence-on-sport/ 